\title{
On the investigation of Risk Management Practices in Software Product Lines
}

\author{
Luanna Lopes Lobato ${ }^{1,2}$, Ivan do Carmo Machado ${ }^{3}$, Paulo Anselmo da Mota \\ Silveira Neto ${ }^{1}$, Eduardo Santana de Almeida ${ }^{3}$, Silvio Romero de Lemos Meira ${ }^{1}$ \\ ${ }^{1}$ Informatics Center, Federal University of Pernambuco (UFPE) \\ Caixa Postal 7851 - 50.740-560 - Recife, PE - Brazil \\ ${ }^{2}$ Computer Science Department, \\ Federal University of Goiás (UFG) - Catalão, GO - Brazil \\ ${ }^{3}$ Computer Science Department, \\ Federal University of Bahia (UFBA) - Salvador, BA - Brazil \\ $\{1 l l$, pamsn, srlm\}@cin.ufpe.br, \{ivanmachado, esa\}@dcc.ufba.br
}

\begin{abstract}
Explicit Risk Management (RM) is an open field in Software Product Line (SPL) Engineering research. Just a few studies can be found in the literature that address RM practices. The scenario is even worse when industry projects come into play. There is a lack of empirical studies presenting which RM practices can be applied into real-world projects so as to maximize the quality of risk information. Therefore, we designed this study with the goal of providing initial insights towards addressing this open issue, by investigating the behavior of RM practices in an SPL project. We performed a case study aiming at analyzing aspects surrounding RM for SPL, such as risk occurrence, mitigation and contingency strategies, and risk assessment. Our results points out to a pool of 17 risks that should be considered during the development SPL projects.
\end{abstract}

\section{Introduction}

Software Product Line Engineering has proven to be a feasible strategy for minimizing development costs and time-to-market, and maximizing quality and productivity as well. SPL is based on a set of systems that share a common, managed set of features satisfying the specific needs of a particular market segment or mission and that are developed from a common set of core assets in a prescribed way (Clements and Northrop, 2001). Thus, instead of analyzing and implementing software artifacts anew for all products, e.g., a new customer request, it is more cost-effective to develop the core architecture, which contains the common software artifacts once, and specify the variable parts beforehand, and reuse these in multiple systems, thus reducing the overall development cost and achieving the aforementioned benefits (Habli and Kelly, 2007).

Indeed, the SPL benefits do not come free. They demand mature software engineering, planning, adequate practices of management and development, as well as the ability to deal with organizational issues and architectural complexity (Birk and Heller, 2007). Thus, even being SPL an important strategy for systematic software reuse, it is particularly complex, raising specific and advanced challenges for engineering and management. This development paradigm involves the management of 
variability and commonalities among several applications, which increase its complexity, when compared to the single system development (SSD) approach (Birk and Heller, 2007).

The SPL adoption involves major initial upfront investments and considerable risks may be associated with it. It requires time and systematic planning to present positive results, otherwise, the investment can be lost due to failures in the project. According to Birk and Heller (2007), if these points are not considered, the SPL success will be missed. In addition, technical capabilities alone cannot guarantee the success of an SPL adoption program, and the development should be supported by auxiliary methods, which helps the project stakeholders to make decisions related to the actions to be performed during the project, in order to analyze the possible risks that may arise from such decisions (Lobato, 2012).

Risk Management (RM) emerges as a significant approach to support this decision process, since its inherent practices aid in software development control practices, which prevent exposure to problems that are likely to occur in the software development project (Lobato, et al. 2012a). Management is a central task for SPL, and RM is required to facilitate and monitor its activities (Birk and Heller, 2007). This way, it identifies, addresses, and eliminates risky items before they become a threat to software development (Boehm, 1989). Due to the complexity associated with the SPL development, as it involves considerable risks, and the fact that these risks can be spread over the whole project, RM is an essential practice (Lobato et al., 2010).

As a way to contribute to RM in the SPL field, we present a case study performed on the basis of an SPL project, developed in an academic environment. The project was focused on developing an SPL in the domain of conference management systems. As a result, we identified risks, and defined mitigation and contingency strategies. We believe these results to be essential to understand these fields and, further, to define specific RM approaches to SPL, since there is a lack of evidences in the literature, as reported in an earlier investigation. As a limitation of this work, we can cite the project developed, which was conducted in an academic environment. This can lead to threats in the project, as further discussed in the Section 8.

The remainder of the paper is structured as follows. Section 2 presents related work. Sections 3 and 4 describe the study context and design. Section 5 presents the application of the main RM activities to perform the SPL project. The analysis of the results is presented in Section 6. In section 7, a discussion on the basis of the results is presented. Section 8 addresses the threats to validity of this study. Finally, in section 9, we conclude this work with final remarks.

\section{Related Work}

We can mention, as related work, two case studies about RM in SPL engineering:

The first one is a case study performed in a company that develops software in the healthcare management systems domain. Risks were identified during the project, their likelihood and impact, as well as the mitigation and contingency strategies used to avoid and solve those (Lobato et al., 2012b). A set of basic RM activities was followed in order to have some guide during the application of RM to develop the SPL project, which is the same as the one applied in the current research presented in this paper. 
The second case study presents the evolution of SSD to SPL, also performed in an industrial environment, showing details on how the evolution took place and the experiences collected through the study (Quilty and Cinnéide, 2011). The advantages presented with the SPL concepts were analyzed to develop the product, named as Blade. A customizable and configurable approach, that is comparable to the SPL development, was performed to the Blade product. By analyzing empirical data collected over a tenyear period, it was noticed some gains in terms of efficiency and quality with the use of SPL engineering, while costs have been reduced.

Like in the previous work, this investigation can be considered as one more step towards the understanding of RM in SPL, based on evidences collected through an academic case study. This study is based on lessons learned identified from our experience to develop systems using SPL as development paradigm.

\section{Study Context}

In this study we consider the RiSE Chair Product Line (RCPL) project, as our study target. This SPL project, in the domain of conference management systems, comprises assets to control the life cycle of reviews of conferences and journals. Its focus was to assemble three products from the core asset base, which met specific requirements, as next detailed.

The RCPL was conceived based on the analysis of commonality and variability from largely used conference management systems, such as CyberChair, EasyChair, and JEMS-SBC. The products assembled from the core asset base were: i) $\boldsymbol{R}$-Chair Plus: a complete system for papers revision and submission, which is targeted at journals and conferences. It also includes a module for event management; ii) $\boldsymbol{R}$-Chair: targeted at papers submission in Journals and their management, simplifying the submission, revision and management procedures, and iii) Smart $\boldsymbol{R}$-Chair: targeted at papers submission in conferences and its management. It aims to simplify the submission, revision and offer resources to manage conferences.

The project comprises a set of 41 features, previously identified in the scoping analysis. The code was developed with the J2EE platform, including Spring and Hibernate, implementing variability in 8 core components. As Database Management System, an instance of MySQL was used. The project was developed following the RiPLE, which covers the whole SPL development lifecycle. In this paper, the focus was on the use of the processes for scoping and requirements, henceforth named as disciplines. Firstly, the RiPLE-SC, which is mainly responsible for analyzing whether it is worth to create an SPL based on specific scenario/goals; and next, the RiPLE-RE (Lobato, 2012), which is focused on defining and managing requirement-related artifacts.

In order to characterize the risks identified during the execution of the chosen processes, the RM activities defined in (Boehm, 1989) were used, which were adapted to our context, as further explained.

\section{Design of the Study}

This study was performed as a case study and it was designed and reported based on the guidelines defined in (Runeson and Höst, 2009). Five steps were performed, as follows: 
1) case study design; 2) preparation for data collection; 3) evidence collection; 4) analysis of collected data; and 5) reporting. Throughout this section, we detail how we collected and analyzed data, and we also report on the complementary tasks performed to reach the stated goals.

The research question this study was aimed at answer is stated as follows: Which are the risks, their likelihood and their impact, and how can we mitigate them? This question aims to identify risks, their classification, and the likelihood of their occurrence and impact on the project. Our goal was to summarize ways to manage and mitigate the risks identified in an academic SPL project.

\subsection{Subjects Selection}

The subjects were 3 M.Sc. and 3 Ph.D. students involved with the SPL project, who assumed the roles of Software Engineer, Project Manager and Risk Manager. Every subject was required to fill in a background questionnaire, in which they were supposed to describe their academic and industry experience, to perform this case study.

By analyzing the questionnaires, we noticed that many subjects had previously worked in some industry projects, however, with low (or none, in some cases) experience in software reuse, e.g., component-based development, and SPL. In sum, all subjects were involved in academic research in SPL, which could make easier the understanding of underlying concepts. As a matter of fact, several subjects reported some experience in industry projects (only 2 out of 6 - subjects 5 and 6 - did not report any experience). Only two reported experience on RM in the academy and industry, presenting low experience. Regarding Evolution Management (EM), the majority had low experience in either academic or industry projects. Regarding Requirements Engineering (RE), the majority reported knowledge gained in university classes, but rather either low or absent industrial practice. These latest were analyzed since EM has direct implications on RM, due to change management practices. On the other hand, RE is also important, since the posed complexity of its activities may lead a project to experience delays in its execution, when not accurately managed.

Regarding the low experience presented in academic and industry projects, we reinforced the need of trainings to the stakeholders on SPL before starting a project. This is important to make them familiar with the development strategy to be analyzed, as well as with the tools, processes and methods involved in the project development.

In the initial phase of the project, roles were distributed among the subjects, according to their experience, and particular interest as well. Considering the reduced number of subjects, only the essential roles were used according to the adopted processes (scoping and requirements). One subject was selected to manage the risks, and the others just helped when a risk was observed or a resolution is required to some problem. Two Ph.D. acted as external stakeholders, with the role of customers of the SPL, and they were responsible for validating the deliverables, as well as worked as domain experts.

The project development consumed about 590 working/hours, as next detailed in Table 1. Since RM practices are orthogonal to all others disciplines performed, i.e., such practices must be performed in every development phase, it was not possible to state a specific value for the effort required to develop risk management in this project. Table 1 shows a high effort required to develop the early development disciplines (scoping and 
requirements). Such values can be justified by the importance of these phases to the project, since essential tasks are strictly associated with them. However, the large amount of time can also be explained by the lack of knowledge about the domain by the subjects, who had to investigate domain specific concerns.

Table 1. Amount of time devoted to each development discipline

\begin{tabular}{|c|c|c|c|c|c|c|c|c|}
\hline Effort & Hours & $\%$ & Effort & Hours & $\%$ & Effort & Hours & $\%$ \\
\hline Scoping & 111.52 & 18.93 & Design & 74.30 & 12.61 & Evolution & 7.20 & 1.24 \\
\hline Requirement & 217.01 & 36.73 & Implementation & 149.30 & 25.3 & Others & 30.40 & 5.19 \\
\hline \multicolumn{7}{|c|}{ Total } & 589.73 & 100 \\
\hline
\end{tabular}

\subsection{Data Collection Procedure}

The use of multiple sources of evidence in a case study allows an investigator to address a broader range of historical and behavioral issues, in order to make any finding or conclusion of the study more convincing and accurate (Yin, 2003). Six sources of evidences are identified by Yin (2003): documentation, archival records, interviews, direct-observation, indirect-observation and focus group.

We used different sources of data collection to identify insights on the SPL development. According to Runeson and Höst (2009), several sources in a case study limit the risks associated with one interpretation: $i$ ) we firstly monitored the project meetings in order to identify insights and, real issues and risks - this was made through direct and indirect observation, and through the emails exchanged among team members; ii) secondly, we analyzed similar systems to identify features that our product line should complain - through the documentation and archival records; and iii) finally, we analyzed the subjects through the application of interviews and focus group.

\subsection{Data Analysis Procedure}

The data analysis process consisted of three main steps: $i$ ) the events in the context of the case study were captured by the researchers, through observations and interviews; $i$ ) the notes and interview audio recordings were recorded to be following transcribed; and iii) the quotes were coded, grouped, tabulated and crossed among them and then the individual results were identified from these groups.

Coded data was stored in tables together with different risk attributes, such as: ID, description, impact, likelihood, SPL phases, mitigation strategy used, identifier and the sources of the occurrence. It was important to make traceability feasible. All these tables were then used to identify results and reach conclusions.

Three principles were considered in order to maximize the sources of evidence, as defined by Yin (2003): $i$ ) the use of multiple sources of evidence; $i$ ) the creation of a case study database; and iii) the maintenance of a chain of evidence.

\section{Applying Risk Management Activities}

The project comprised a number of workshops. All subjects enrolled in the project must attend the workshops. These were held regularly, and were aimed at presenting the status of the project, by means of discussing what, at a given moment, could be considered as strong points or drawbacks. In this sense, such sessions were used to discuss the risk management activities, as well as to discuss risk related issues. 
Initially, the existing conference management systems were analyzed in order to identify their features. The analysis was performed during the scoping phase, in which subjects were responsible for identifying the main features and build the product map and the feature model. Then, the requirements phase came into play with the elicitation, description and validation of use cases and requirements.

Figure 1 presents the workflow of the RM activities performed, which are next defined: Risk Identification: Risks were identified during the SPL execution; Risk Documentation: Risks were documented to give support to their further assessment; Risk Analysis: Responsible for assessing the likelihood and consequences of risks; Risk Planning: Addressed the identified risks, either by avoiding or minimizing their effects in the project; and Risk Monitoring: Risks were regularly assessed and mitigation plans were revised as more information about the risks became available.

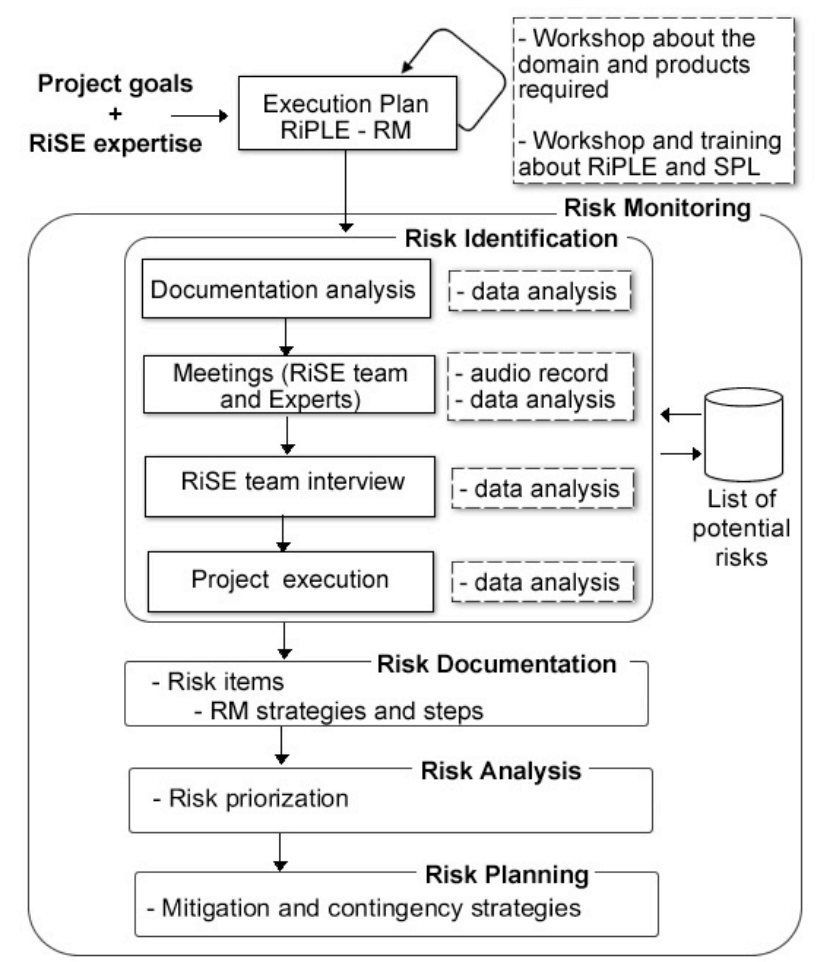

Figure 1. Risk Management execution

After identifying the risks in the project, they were analyzed. At this point, the observations were aimed at understanding the risks likelihood, impact, status and relevance to the project. Based on such information, mitigation and contingency strategies were planned for every identified risk.

The Risk Manager, with the support of a Software Engineer, performed the RM activities. During the workshops, the subjects discussed how the risk would be identified, and also workshops were used to define the techniques to identify the risks and the documentation that would be analyzed. The Risk Manager was also responsible for documenting the lessons learned and decisions taken. Such information, together with any message exchanged by project members (e.g., through mailing lists) could be sources of possible risks to the project, and thus were considered in terms of analysis. 


\section{Results}

This section describes the issues identified during the execution of the case study, which could be lead to a risk.

We herein define strategies to be applied in order to reduce the likelihood of risks caused by any of the identified issues. The list of risks, together with the detailed documentation, in terms of impact and likelihood analysis can serve as a set of recommended practices to be considered during the execution of an SPL project, in order to avoid or minimize future problems occurrences.

\subsection{Risk Identification}

Data were collected through interviews, meetings, focus group, observations, and analysis of available documentation and audio records (gathered from the interviews with internal stakeholders). All these data collection strategies were combined and analyzed to answer our research question, as well as to identify the strengths and drawbacks of the risk management practices applied in the project.

As earlier described, risk identification was performed during the initial phases of the project, namely scoping and requirements. The identification considered a pool of 17 risks, as presented in Table 2. These are risks related to SPL and generic projects. Thus, these risks should be considered in order to avoid some problems that can become real to the project. We can cite the risks R8, R11 and R17 as related to SPL.

The identified risks typically fall into one of the categories: problems or opportunities for improvement. The risks that are characterized by problems are the events that occur and might cause a negative damage to the project. On the other hand, risks classified as opportunities are the ones that occur and might cause positive influence on the project, in terms of providing some improvement.

\subsection{Risk Documentation}

Documentation plays an important role in capturing tacit knowledge, particularly when there is a high rate of staff turnover, i.e., when a team member leaves, valuable knowledge, good practices and lessons learned could be lost (Lobato, et al., 2010).

On the other hand, the lack of documentation is a problem in many software projects. In Schmid (2002), the author claims that software projects are usually not sufficiently documented. The risk documentation activity is used to keep historical data about the identified risks and provide insights about how they can be avoided or mitigated, or even which mitigation plans could be applied when the risk is materialized. The documentation is also important to support RM in SPL. It provides important insights about the project and can capture mistakes as a strategy to avoid them to occur again, either in the same or future projects. Repetition of mistakes is particularly true for SPL development as several products are typically derived from the same platform.

The documentation contains the risk description, potential and implemented controlling actions, as well as, the history of the risk and its impact on the project. It also contains information for both operational purposes, i.e., actions controlling monitoring, and documentation purposes, enabling someone to learn from the risks for future projects. Table 2 shows the complete list of risks and their descriptions. 
Table 2. Identified Risks

\begin{tabular}{|l|l|l|}
\hline ID & \multicolumn{1}{|c|}{ Risks Name } & \multicolumn{1}{c|}{ Risk Description } \\
\hline R1 & Missed schedule & The schedules are late due some bad planning and/or management. \\
\hline R2 & Lack of support tools & Lack of tools to support the project development. \\
\hline R3 & $\begin{array}{l}\text { Inadequate technology, methods and } \\
\text { process }\end{array}$ & $\begin{array}{l}\text { Inadequate technology, methods and processes that are used during project } \\
\text { development. }\end{array}$ \\
\hline R4 & Inadequate technical documentation & Lack of documentation, documentation problems, or deprecated documentation \\
\hline R5 & Absence of domain experts & Lack of domain experts to validate the artifacts and give directions for the team. \\
\hline R6 & Immature process & The process is not well defined or is not defined in a maturity satisfactory level. \\
\hline R7 & Inadequate communication & Lack of communication during the SPL activities execution. \\
\hline R8 & Inadequate features definition & The features are not clearly defined, complete or correct. \\
\hline R9 & Bad practices in management & There is no adequate project management. \\
\hline R10 & Inadequate training & Project team is not provided with adequate training to perform the project. \\
\hline R11 & Core assets instability & Core assets are subject to frequent change requests. \\
\hline R12 & Failure in requirements identification & Incomplete and incorrect requirements and specifications. \\
\hline R13 & Infrastructure unavailability & Lack of available resources, such as computers, network, etc. \\
\hline R14 & Lack of team commitment & Lack of team commitment and/or pro-activity. \\
\hline R15 & Rework & Tasks performed need to be done again. \\
\hline R16 & Not qualified staff & Team does not have suitable knowledge to perform the project with quality. \\
\hline R17 & Inadequate core assets traceability & Traceability among artifacts is not as adequate as necessary. \\
\hline
\end{tabular}

In addition, characteristics such as status and relevance were also considered in this analysis. The possible values a risk can be attributed to, are next listed. It is worth mentioning that the risk manager defines such values in accordance with the whole team, during validation meetings: Likelihood: 1 (Low), 2 (Medium) and 3 (High); Impact: 1 (Low), 2 (Medium) and 3 (High); Status: F (Fixed), C (Canceled) and P (Pending); Relevance: L (Low), M (Medium) and H (High).

This classification is useful to control and manage the risks during the software project development. Table 3 presents the results from the Risk Analysis activity, where $\mathrm{L}$ means likelihood, I impact, S status, and $\mathrm{R}$ relevance.

Table 3. Risks Likelihood and Impact

\begin{tabular}{|c|c|c|c|c|c|c|c|c|c|c|c|}
\hline ID & Risks & $\mathbf{L}$ & I & $\mathbf{S}$ & $\mathbf{R}$ & ID & Risks & $\mathbf{L}$ & I & $\mathbf{S}$ & $\mathbf{R}$ \\
\hline $\mathrm{R} 1$ & Missed schedule & 2 & 3 & $\mathrm{~F}$ & $\mathrm{H}$ & R10 & Inadequate training & 1 & 2 & $\mathrm{~F}$ & $\mathrm{M}$ \\
\hline $\mathrm{R} 2$ & Lack of support tools & 1 & 2 & $\mathrm{C}$ & M & R11 & Core assets instability & 2 & 3 & $\mathrm{P}$ & $\mathrm{H}$ \\
\hline R3 & $\begin{array}{l}\text { Inadequate technology, methods } \\
\text { and process }\end{array}$ & 1 & 2 & $\mathrm{C}$ & $\mathrm{M}$ & R12 & $\begin{array}{l}\text { Failure in requirements } \\
\text { identification }\end{array}$ & 2 & 3 & $\mathrm{P}$ & $\mathrm{H}$ \\
\hline $\mathrm{R} 4$ & Inadequate technical documentation & 2 & 3 & $\mathrm{P}$ & $\mathrm{H}$ & R13 & Infrastructure unavailability & 1 & 2 & $\mathrm{~F}$ & $\mathrm{H}$ \\
\hline R5 & Absence of domain experts & 3 & 3 & $\mathrm{P}$ & $\mathrm{H}$ & R14 & Lack of team commitment & 1 & 3 & $\mathrm{~F}$ & $\mathrm{H}$ \\
\hline R6 & Immature process & 3 & 3 & $\mathrm{~F}$ & $\mathrm{H}$ & R15 & Rework & 1 & 2 & $\mathrm{~F}$ & $\mathrm{M}$ \\
\hline R7 & Inadequate communication & 1 & 2 & $\mathrm{~F}$ & $\mathrm{H}$ & R16 & Not qualified staff & 2 & 3 & $\mathrm{P}$ & $\mathrm{H}$ \\
\hline R8 & Inadequate features definition & 2 & 3 & $\mathrm{~F}$ & $\mathrm{H}$ & $\mathrm{R} 17$ & Inadequate core assets traceability & 1 & 3 & $\mathrm{~F}$ & $\mathrm{H}$ \\
\hline R9 & Bad practices in management & 1 & 3 & $\mathrm{~F}$ & $\mathrm{M}$ & & & & & & \\
\hline
\end{tabular}

In order to validate these results, a meeting was held with the team members. These had to solve any disagreements regarding risk characteristics classification. By disagreements, we mean the cases in which a risk was classified in a wrong way, in terms of having only considered a specific scenario in which the risk was materialized, but instead should have an agreement considering all possible scenarios in the project, in terms of, e.g., the development phase or activity.

\subsection{Risk Planning}

A RM plan was built in order to support the planning activity. It encompassed mitigation strategies, contingency plans and some information about risks occurrence. The RM was performed using a spreadsheet, however, due to the number of risks and the amount of information generated, it was a tough activity. Thus, we proposed the use 
of a RM tool, as defined in Cavalcanti et al. (2011), to manage, and visualize information and traceability in the project.

The RM tool served to understand the relationships among the risks identified, facilitate the evolution and maintenance of the RM effort, and also to document the project risks. In addition, since the RM process is a continuous activity, it is necessary to keep track of historic information. Thus, risks likelihood and impact are documented according to their occurrence. As a way to perform risk planning, some strategies were defined to mitigate the risks as showed in Table 4. Related to the mitigation and contingency strategies, some of them are actions related to SPL. The following risks present actions specific to SPL strategies: R2, R4, R5, R8, R11 and R16.

Table 4. Mitigation and Contingency Strategies

\begin{tabular}{|c|c|c|}
\hline ID & Mitigation & Contingency \\
\hline R1 & $\begin{array}{l}\text {-The activities must be distributed among all stakeholders and } \\
\text { keep the schedule in the planned dates; } \\
\text {-Previous planning the project, involving the experts in order to } \\
\text { define deadlines that are possible to reach; } \\
\text {-Using functional metrics to quantify and control growth in user } \\
\text { requirements; } \\
\text {-Accurate historical data collection and measure of project } \\
\text { schedules; }\end{array}$ & $\begin{array}{l}\text {-Reduce the functions of the software, or } \\
\text { delaying some functions to a future release; } \\
\text {-Reduce the project quality (not recommended); } \\
\text {-Adding stakeholders to optimize the activities; } \\
\text {-Increase the number of the worked hour; } \\
\text {-Require greater involvement of each } \\
\text { stakeholder; } \\
\text {-Redefine schedules date. }\end{array}$ \\
\hline R2 & $\begin{array}{l}\text {--Define tool that can help to manage the whole project, } \\
\text { identifying and controlling the problems; } \\
\text {-Choose maturity tools and technologies that support the } \\
\text { development based on SPL. }\end{array}$ & $\begin{array}{l}\text {-Provide meeting with experts to highlight which } \\
\text { are the tools and methods; } \\
\text {-Awareness the stakeholders to use the tools and } \\
\text { methods defined. }\end{array}$ \\
\hline R3 & $\begin{array}{l}\text {-Apply surveys to identify the methods that the managers must } \\
\text { follow to develop the project in a correct way; } \\
\text {-Choose maturity methods that support the SPL development. }\end{array}$ & $\begin{array}{l}\text {-Assess the method before adopt it; } \\
\text {-Provide meeting with experts in order to validate } \\
\text { the method. }\end{array}$ \\
\hline R4 & $\begin{array}{l}\text {-Create a pattern to the documents that should follow the } \\
\text { organization pattern and not be defined for each project } \\
\text { separately. }\end{array}$ & $\begin{array}{l}\text {-Schedule a person to be responsible for the } \\
\text { suitability of documents. }\end{array}$ \\
\hline R5 & $\begin{array}{l}\text {-Meetings should be schedule in anticipation with the domain } \\
\text { experts in order to collect the requirements necessary that } \\
\text { should compose the project. }\end{array}$ & $\begin{array}{l}\text {-Involve other stakeholders during the discussion } \\
\text { with experts, to make it an expert too, and to } \\
\text { substitute the expert when necessary. }\end{array}$ \\
\hline R6 & $\begin{array}{l}\text {-Before starting the development, set all processes related to the } \\
\text { current phase to a satisfactory level of maturity. }\end{array}$ & $\begin{array}{l}\text {-Make meeting to review the process and decide } \\
\text { if it must be followed or abandoned. }\end{array}$ \\
\hline R7 & $\begin{array}{l}\text {-Facilitate communication between the team during the } \\
\text { meetings to encourage the stakeholders to participate actively; } \\
\text {-Schedule meetings with the client in a regular period to show } \\
\text { what is being done and enhance the customer's wishes. }\end{array}$ & $\begin{array}{l}\text {-Clarify the points that not understood by } \\
\text { everyone involved in the project; } \\
\text {-If someone cannot attend the meeting, schedule } \\
\text { another day or send emails with feedback. }\end{array}$ \\
\hline R8 & $\begin{array}{l}\text {-Promote meetings in order to revise the features definition and } \\
\text { define how they differ from other artifacts developed; } \\
\text {-Apply the feature modeling technique to facilitate the } \\
\text { management. } \\
\text {-Facilitate the exploration of variation point between the } \\
\text { requirements used to implement new products from the same } \\
\text { family. }\end{array}$ & $\begin{array}{l}\text {-Redo the features identification according the } \\
\text { project characteristics, describing the features in } \\
\text { a clearly way, refine the features set. }\end{array}$ \\
\hline R9 & $\begin{array}{l}\text {-Establishing tangible and reasonable criteria for managerial } \\
\text { selection, appraisals, and promotion; } \\
\text {-Establishing opinion surveys; } \\
\text {-Define mentorship program, to pass the knowledge to } \\
\text { managers. }\end{array}$ & $\begin{array}{l}\text {-Distribute the activities to the stakeholders } \\
\text { according to their difficulty degree; } \\
\text {-Define stakeholder for each activity, based on } \\
\text { the profile and skill of each one. }\end{array}$ \\
\hline R10 & $\begin{array}{l}\text {-Build a training plan, in advance, that need be followed in the } \\
\text { beginning of the project; } \\
\text {-Conduct training sessions with stakeholders about the } \\
\text { processes and issues necessary before and during the course of } \\
\text { the project. }\end{array}$ & $\begin{array}{l}\text {-Provide training to prepare the stakeholders; } \\
\text {-Find cooperation of the group members that has } \\
\text { greater ease to help those with more difficulty. }\end{array}$ \\
\hline R11 & $\begin{array}{l}\text {-Clearly define the project goals, what is expected to be achieve, } \\
\text { which are the necessary features and requirements; } \\
\text {-The scope should be well defined before the core asset } \\
\text { development. }\end{array}$ & $\begin{array}{l}\text {-Check the assets that have been changed and } \\
\text { looked for those that present dependences, in } \\
\text { order to make the necessary changes; } \\
\text {-To clear the project goals. }\end{array}$ \\
\hline
\end{tabular}


Table 4 - continued from previous page

\begin{tabular}{|c|c|c|}
\hline ID & Mitigation & Contingency \\
\hline $\mathrm{R} 12$ & $\begin{array}{l}\text {-Conduct a continuous requirement validation process, mainly } \\
\text { after the changes in the requirements; } \\
\text {-Clearly plan the schedule, and implement first the essential and } \\
\text { stable requirements. }\end{array}$ & $\begin{array}{l}\text {-To manage the scope changes that can reflect in } \\
\text { the requirements; } \\
\text {-To control the requirement changes in order to } \\
\text { avoid that the scope process is not followed. }\end{array}$ \\
\hline $\mathrm{R} 13$ & $\begin{array}{l}\text {-Plan the need for the infrastructure, considering all user } \\
\text { requirements, to avoid misuse of services. }\end{array}$ & $\begin{array}{l}\text {-Redefine the tasks and schedules so that } \\
\text { everyone can work with available resources. }\end{array}$ \\
\hline R14 & $\begin{array}{l}\text {-Select people with a good history (data from past projects) in } \\
\text { terms of commitment and proactivity. } \\
\text {-Flexibility in work hours, enabling a goal-oriented } \\
\text { environment. } \\
\text {-Provide reports warning of delays in the project due to lack of } \\
\text { commitment of the team, making stakeholders aware on their } \\
\text { individual commitment. }\end{array}$ & $\begin{array}{l}\text {-Schedule meetings look for the schedule with } \\
\text { the largest number of people available; } \\
\text {-Mark extra meetings to relocation of human } \\
\text { resources, thus, if a stakeholder cannot work } \\
\text { other one would substitute. }\end{array}$ \\
\hline R15 & $\begin{array}{l}\text {-Documenting the experiences obtained during the project } \\
\text { developed, to be used in future projects. } \\
\text { - Define tasks to specific stakeholders and report this, to other } \\
\text { stakeholder do not perform the same activities. }\end{array}$ & $\begin{array}{l}\text {-Make meeting to do clear the project goal, in } \\
\text { order to avoid rework due the development of } \\
\text { inadequate functionalities; }\end{array}$ \\
\hline R16 & $\begin{array}{l}\text {-Select qualified people to the project, according to their skills. } \\
\text {-Find people who have experience in SPL development and in } \\
\text { the project domain. } \\
\text {-Encourage and provide conditions for those involved in the } \\
\text { project to study and solve their difficulties. }\end{array}$ & $\begin{array}{l}\text {-Training should be performed. } \\
\text {-Evaluate the professional who does not meet } \\
\text { expectations and decide on its exclusion. } \\
\text {-Choose language and technologies that the group } \\
\text { is more familiar to implement the project. }\end{array}$ \\
\hline R17 & $\begin{array}{l}\text {-Use support tools to enable traceability among artifacts. } \\
\text {-Document every change in the project, analyzing its impact in } \\
\text { terms of traceability. Changes must be managed. }\end{array}$ & $\begin{array}{l}\text {-Make meeting to map the artifacts and their } \\
\text { traceability. }\end{array}$ \\
\hline
\end{tabular}

\subsection{Risk Monitoring}

Risk Monitoring is a crucial activity in the RM process, since new risks can occur during the project, or even the ones already solved can return to be harmful to the project success. As aforementioned, these characteristics can have their values changed, which could have some impact in the project. As new risk data are included in the risk plan, the risks have to be reviewed and new priorities established. Hence, monitoring should be a continuous activity that encompasses the whole project life cycle.

In this way, for the purpose of this project, the risks were monitored in order to reduce the likelihood of occurrence that would negatively influence the project. Risk Monitoring was performed in an interval of three days during the project. It was observed that some risks assumed different values for likelihood and impact during monitoring activities. The likelihood and impact of the risks could increase or decrease, depending on the activity performed.

In order to analyze the most dangerous risks to the project, we defined the severity of the risks, which is based on the multiplication of the likelihood and the impact that the risk presented. A more detailed analysis is presented in the following section.

\section{Discussion}

This section presents a discussion based on the results obtained through the execution of this case study. It was possible to confirm the importance in performing RM in SPL projects, since if risks are not correctly managed, the project could be compromised.

The identified risks were classified in the SPL essential disciplines proposed by the CMU/SEI (Northrop, 2002): Core Assets Development (CAD), Product Development (PD), and Management (M). Table 5 presents this analysis. 
Table 5. Mitigation and Contingency Strategies

\begin{tabular}{|c|c|c|c|c|c|c|c|c|c|}
\hline \multirow{2}{*}{ ID } & \multirow{2}{*}{ Risks Name } & \multicolumn{3}{|c|}{ Risk Classification } & \multirow{2}{*}{ ID } & \multirow{2}{*}{ Risks Name } & \multicolumn{3}{|c|}{ Risk Classification } \\
\hline & & CAD & PD & $\mathbf{M}$ & & & CAD & PD & $\mathbf{M}$ \\
\hline R1 & Missed schedule & $\sqrt{ }$ & $\sqrt{ }$ & & $\mathrm{R} 10$ & Inadequate training & $\sqrt{ }$ & $\sqrt{ }$ & $\sqrt{ }$ \\
\hline $\mathrm{R} 2$ & Lack of support tools & $\sqrt{ }$ & $\sqrt{ }$ & $\sqrt{ }$ & R11 & Core assets instability & $\sqrt{7}$ & $\sqrt{ }$ & \\
\hline R3 & $\begin{array}{l}\text { Inadequate technology, } \\
\text { methods and process }\end{array}$ & & & $\boldsymbol{v}$ & $\mathrm{R} 12$ & $\begin{array}{l}\text { Failure in requirements } \\
\text { identification }\end{array}$ & & & \\
\hline R4 & $\begin{array}{l}\text { Inadequate technical } \\
\text { documentation }\end{array}$ & & & & $\mathrm{R} 13$ & $\begin{array}{l}\text { Infrastructure } \\
\text { unavailability }\end{array}$ & & & \\
\hline R5 & Absence of domain experts & $\sqrt{ }$ & $\sqrt{ }$ & $\sqrt{ }$ & R14 & Lack of team commitment & $\sqrt{ }$ & $\sqrt{ }$ & $\sqrt{ }$ \\
\hline R6 & Immature process (scoping) & $\sqrt{ }$ & & & $\mathrm{R} 15$ & Rework & $v$ & $\sqrt{ }$ & $\sqrt{ }$ \\
\hline R7 & Inadequate communication & & & $\sqrt{ }$ & R16 & Not qualified staff & $\sqrt{ }$ & $\sqrt{ }$ & \\
\hline R8 & Inadequate features definition & 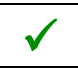 & & & $\mathrm{R} 17$ & $\begin{array}{l}\text { Inadequate core assets } \\
\text { traceability }\end{array}$ & & & \\
\hline R9 & Bad practices in management & & & $\sqrt{ }$ & & & & & \\
\hline
\end{tabular}

Based on this analysis, it was observed that some risks were identified, and fit into any SPL activity. Thus, it is important that RM be performed in the whole SPL. Another important aspect refers to the likelihood and impact analysis. In some situations a risk can present a both low occurrence likelihood and impact for a given project. In this case, it is necessary to analyze the costs to solve the risks, and how it may impact on the project. Sometimes, the costs involved in the resolution of the risk are higher than their occurrence, so it is better that the risk occurs in the project.

Besides identification, risk monitoring is also an important task. Whenever a risk becomes real in a project, even after corrective actions, it may occur again, or even, it might imply the occurrence of another risk. Table 6 presents the results of risk monitoring, where the likelihood (L) and impact (I) were analyzed during the whole scoping and requirement disciplines, based on Low (1), Medium (2) and High (3).

\section{Table 6. Risk Monitoring}

\begin{tabular}{|c|c|c|c|c|c|c|c|c|c|c|c|c|c|c|c|c|c|}
\hline \multirow{3}{*}{ ID } & \multicolumn{4}{|c|}{ Scoping } & \multicolumn{4}{|c|}{ Requirements } & \multirow{3}{*}{ ID } & \multicolumn{4}{|c|}{ Scoping } & \multicolumn{4}{|c|}{ Requirements } \\
\hline & \multicolumn{2}{|c|}{ Jan. } & \multicolumn{2}{|c|}{ Feb. } & \multicolumn{2}{|c|}{ March } & \multicolumn{2}{|c|}{ April } & & \multicolumn{2}{|c|}{ Jan. } & \multicolumn{2}{|c|}{ Feb. } & \multicolumn{2}{|c|}{ March } & \multicolumn{2}{|c|}{ April } \\
\hline & $\mathrm{L}$ & I & $\mathrm{L}$ & I & $\mathrm{L}$ & I & $\mathrm{L}$ & I & & $\mathrm{L}$ & I & $\mathrm{L}$ & I & $\mathrm{L}$ & I & $\mathrm{L}$ & I \\
\hline $\mathrm{R} 1$ & 2 & 3 & 1 & 3 & 1 & 3 & 1 & 3 & R10 & 1 & 2 & 1 & 1 & 1 & 1 & 1 & 1 \\
\hline $\mathrm{R} 2$ & 1 & 2 & 1 & 2 & - & - & - & - & R11 & 2 & 3 & 1 & 3 & 1 & 3 & 1 & 3 \\
\hline R3 & 1 & 2 & 1 & 2 & - & - & - & - & R12 & 2 & 3 & 1 & 3 & 1 & 3 & 1 & 3 \\
\hline $\mathrm{R} 4$ & 2 & 3 & 1 & 3 & 1 & 2 & 1 & 1 & R13 & 1 & 2 & 1 & 2 & - & - & - & - \\
\hline R5 & 3 & 3 & 3 & 3 & 3 & 2 & 3 & 1 & R14 & 1 & 3 & 1 & 3 & - & - & - & - \\
\hline R6 & 3 & 3 & - & - & 1 & 1 & - & - & R15 & 1 & 2 & 1 & 2 & 1 & 2 & - & - \\
\hline R7 & 1 & 2 & - & - & - & - & - & - & R16 & 2 & 3 & 1 & 2 & 1 & 2 & 1 & 2 \\
\hline R8 & 2 & 3 & 2 & 3 & 1 & 3 & 1 & 3 & R17 & 1 & 3 & 1 & 2 & 1 & 2 & - & - \\
\hline R9 & 1 & 3 & 1 & 3 & 1 & 3 & 1 & 3 & & & & & & & & & \\
\hline
\end{tabular}

It was observed that several risks identified in the scoping discipline were solved later in the requirements engineering phase. Some risks such as R5 (Absence of domain experts) were present until the end of the project. It also implied the occurrence of R16 (Not qualified staff) during the whole project. R6 (Immature process) occurred during the beginning of the project and was solved, since the scoping and requirements processes were validated in this study. However, this risk was solved in the second part of each discipline performed, since the process was adapted according to the improvements suggested by the stakeholders involved in this project, so as its status was changed to fixed.

Regarding the mitigation and contingency strategies, we can highlight the risks that presented the status pending. In some cases, even performing mitigation strategies, the solution of the risks cannot be performed immediately, and the effects of their occurrence can be present in the project for a long time, e.g., R1 (Missed Schedule) 
affects different tasks in different development stages. The pending status also can be justified since these risks are those that should be avoided in the beginning of the project and when not avoided, a considerable time is required to solve them. For example, the R4 (Inadequate technical documentation), since we did not had enough documentation about other projects in order to use their results as baseline values in this project. Thus, the decision was to develop the project and construct the documentation during the execution.

Other risks presented also status as pending: R5 (Absence of domain experts), since this study was not an industrial project and there was the lack of a domain expert on the project domain, hence despite mitigation and contingency strategies were defined, the solution of these risks could not be applied in this project. R11 (Core assets instability), as the processes were immature, the core assets developed could suffer changes during the project, thus the status was pending. As a consequence of R5, the risk R12 (Failure in requirements identification) was a recurrent risk to this project. Thus, R12 had the status as pending during the whole period of observation to this project (scoping and requirement disciplines). Regarding R16 (Not qualified staff), this risk was pending because the subjects involved were students with few experience in real-world SPL projects.

Table 7 presents the influences of one risk on the occurrence of others, i.e., if a specific risk occurs, it will imply that others also can occur. We used the following representation: the mark $(\checkmark)$ means that the risk implies on the occurrence of other ones; in cells marked with ( $\left.\otimes^{\otimes}\right)$, the risk does not imply in the occurrence of another one; and $(-)$ refers to as not applied, since the risks influence could not be analyzed because one risk cannot influence on its occurrence.

Table 7. Influence among the risks

\begin{tabular}{|c|c|c|c|c|c|c|c|c|c|c|c|c|c|c|c|c|c|}
\hline Risk & 1 & 2 & 3 & 4 & 5 & 6 & 7 & 8 & 9 & 10 & 11 & 12 & 13 & 14 & 15 & 16 & 17 \\
\hline 1 & 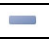 & 8 & ( & $\sqrt{ }$ & $\times$ & $\sqrt{ }$ & $x$ & $\sqrt{ }$ & $\sqrt{ }$ & $\sqrt{ }$ & $\sqrt{ }$ & $\sqrt{ }$ & $x$ & $x$ & $\sqrt{ }$ & 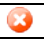 & $\sqrt{ }$ \\
\hline 2 & $\sqrt{ }$ & 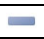 & $\sqrt{ }$ & 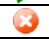 & $\times$ & (x) & 8 & 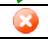 & $\sqrt{ }$ & $\lambda$ & 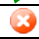 & $x$ & 8 & ( & $\checkmark$ & ג & ( \\
\hline 3 & $\sqrt{ }$ & $\sqrt{ }$ & 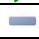 & $x$ & $\times$ & (3) & $x$ & $\sqrt{ }$ & ( & $\sqrt{ }$ & $\sqrt{ }$ & $\sqrt{ }$ & $x$ & $x$ & $\checkmark$ & $\times$ & $\sqrt{ }$ \\
\hline 4 & $\sqrt{ }$ & (x) & 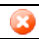 & - & (ג) & (x) & $\sqrt{ }$ & $\sqrt{ }$ & $\sqrt{ }$ & $\sqrt{ }$ & $\sqrt{ }$ & $\sqrt{ }$ & $x$ & $x$ & $\checkmark$ & ( & $\sqrt{ }$ \\
\hline 5 & $\sqrt{ }$ & $(3)$ & $\sqrt{ }$ & $x$ & 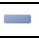 & (x) & ( & $\sqrt{ }$ & (x) & $\sqrt{ }$ & (x) & $\sqrt{ }$ & ( & $x$ & $\sqrt{ }$ & $\sqrt{ }$ & (x) \\
\hline 6 & $\sqrt{ }$ & 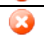 & 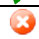 & $\sqrt{ }$ & (ג) & 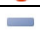 & (x) & $\sqrt{ }$ & $\sqrt{ }$ & $\sqrt{ }$ & $\sqrt{ }$ & $\sqrt{ }$ & (x) & $x$ & $\checkmark$ & $x$ & $\sqrt{ }$ \\
\hline 7 & $\sqrt{ }$ & (x) & ( & $\sqrt{ }$ & $\times$ & (x) & 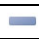 & $\sqrt{ }$ & $\sqrt{ }$ & $\sqrt{ }$ & $\sqrt{ }$ & 7 & ( & 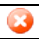 & 7 & $\sqrt{ }$ & \\
\hline 8 & $\sqrt{ }$ & ( & 8 & $\sqrt{ }$ & $(x$ & (x) & 8 & 6 & (x) & $x$ & $\sqrt{ }$ & $\sqrt{ }$ & 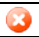 & $x$ & $\sqrt{ }$ & $(3)$ & $\sqrt{ }$ \\
\hline 9 & $\sqrt{ }$ & $\sqrt{ }$ & $\sqrt{ }$ & $\sqrt{ }$ & $\times$ & $\sqrt{ }$ & $\sqrt{ }$ & $V$ & - & $\sqrt{ }$ & $\sqrt{ }$ & $\sqrt{ }$ & $\sqrt{ }$ & $\sqrt{ }$ & $V$ & $\sqrt{ }$ & \\
\hline 10 & $\sqrt{ }$ & ( & $\sqrt{ }$ & $\sqrt{ }$ & (ג) & (3) & 8 & $\sqrt{ }$ & $\sqrt{ }$ & 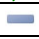 & $\sqrt{ }$ & $\sqrt{ }$ & ( & (ג) & $\sqrt{ }$ & $V$ & \\
\hline 11 & $\checkmark$ & (x) & $x$ & $\sqrt{ }$ & ג & (x) & $x$ & $\sqrt{ }$ & $\sqrt{ }$ & $\alpha$ & $\square$ & $\sqrt{ }$ & (x) & $x$ & $\sqrt{ }$ & $\times$ & $V$ \\
\hline 12 & $\sqrt{ }$ & 8 & 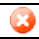 & $\sqrt{ }$ & $\times$ & ( & $x$ & $\sqrt{ }$ & $\sqrt{ }$ & $x$ & $\sqrt{ }$ & - & $x$ & 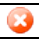 & $\sqrt{ }$ & $\times$ & $\sqrt{ }$ \\
\hline 13 & $\sqrt{ }$ & (x) & ( & $x$ & $\times$ & (3) & $\sqrt{ }$ & $\times$ & $\sqrt{ }$ & $\sqrt{ }$ & $\times$ & $\times$ & 0 & $x$ & $x$ & $\times$ & ( \\
\hline 14 & $\sqrt{ }$ & $\sqrt{ }$ & $\sqrt{ }$ & $\sqrt{ }$ & $\sqrt{ }$ & $\sqrt{ }$ & $\sqrt{ }$ & $\sqrt{ }$ & $\sqrt{ }$ & $\sqrt{ }$ & $\sqrt{ }$ & $\sqrt{ }$ & $\sqrt{ }$ & 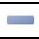 & $\sqrt{ }$ & $\sqrt{ }$ & $\sqrt{ }$ \\
\hline 15 & $\sqrt{ }$ & $(\pi$ & $x$ & $x$ & ( & 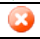 & $x$ & $\sqrt{ }$ & 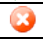 & $x$ & $\sqrt{ }$ & $\sqrt{ }$ & $x$ & $x$ & 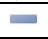 & ( & $\sqrt{ }$ \\
\hline 16 & $\checkmark$ & $\sqrt{ }$ & $\checkmark$ & $\sqrt{ }$ & (ג) & $\sqrt{ }$ & (3) & $\sqrt{ }$ & $\sqrt{ }$ & $\checkmark$ & $\checkmark$ & $\checkmark$ & (2) & $\alpha$ & $\checkmark$ & 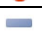 & $\sqrt{ }$ \\
\hline 17 & $\sqrt{ }$ & (x) & 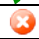 & $\sqrt{ }$ & $\times$ & $x$ & 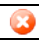 & $\sqrt{ }$ & $\sqrt{ }$ & ( & $\sqrt{ }$ & $\checkmark$ & 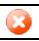 & 3 & $\sqrt{ }$ & (ג) & \\
\hline
\end{tabular}

Due to space constraints, we cannot present the analysis of all risks occurrence, since this can be extracted by the careful analysis of data presented in Table 7. As previously described and confirmed, one risk can lead to the occurrence of another, e.g., R9 (Bad practice in management) implies the occurrence of R8, and so on. However, the opposite is not always true, since R8 (Inadequate features definition), does not lead to the occurrence of R9. Table 8 shows a summary of the risks influences, depicting risks likelihood (L), impact (I), severity (S), and number influences on the risks (IR). 
Table 8. Analysis of the risks

\begin{tabular}{|c|c|c|c|c|c|c|c|c|c|c|c|c|c|c|c|c|c|c|c|}
\hline ID & $\mathbf{L}$ & I & S* & IR & ID & $\mathbf{L}$ & I & S* & IR & ID & $\mathbf{L}$ & I & S* & IR & ID & $\mathbf{L}$ & I & S* & IR \\
\hline $\mathrm{R} 1$ & 2 & 3 & 6 & 9 & R6 & 3 & 3 & 9 & 9 & $\mathrm{R} 10$ & 1 & 2 & 2 & 10 & R14 & 1 & 3 & 3 & 16 \\
\hline R2 & 1 & 2 & 2 & 4 & R7 & 1 & 2 & 2 & 10 & R11 & 2 & 3 & 6 & 7 & R15 & 1 & 2 & 2 & 5 \\
\hline R3 & 1 & 2 & 2 & 8 & R8 & 2 & 3 & 6 & 6 & R12 & 2 & 3 & 6 & 7 & R16 & 2 & 3 & 6 & 12 \\
\hline $\mathrm{R} 4$ & 2 & 3 & 6 & 9 & R9 & 1 & 3 & 3 & 15 & R13 & 1 & 2 & 2 & 4 & R17 & 1 & 3 & 3 & 7 \\
\hline R5 & 3 & 3 & 9 & 7 & & & & & & & & & & & & & & & \\
\hline
\end{tabular}

* based on the initial values found to likelihood and impact.

Based on the results of the risk influence analysis (Lobato, 2012), it was observed that R9 and R14 were the most dangerous risks to this project, since their occurrence implied in the occurrence of others (15 and 16) risks, respectively. Nevertheless, these risks had the severity low if compared with other risks, since their likelihood and impact to the project were considered low. On the other hand, the risks that had less influence are R2 and R13, which impacted on the occurrence of only 4 risks, and $\mathrm{R} 15$, on 5 risks. These risks also presented low severity to the projects, so these should be the last ones to be solved if the project schedule is tight.

The risks that presented the high severity to the project were R5 and R6, with severity level 9. A negative point about the occurrence of these risks is that they influenced a considerable number of risks, i.e., if R5 happens another 6 risks can happen too, and if R6 becomes real another 9 risks also can become real to the project. Thus, these should be priorities in the projects related to the risk mitigation. Regarding the risks that presented the low severity, we can mention R7 and R10, which, despite the severity (2) presented a high influence on the occurrence of another risks, impacting in the occurrence of 10 another risks. Thus, these should also be considered as a priority to the projects.

Despite the occurrence of R16 (Not qualified staff), a relevant aspect regarding the subjects' profile is that the stakeholders involved in the project are students that have been performed research in the SPL field. Due to the experience in SPL, some specific risks could be avoided. Thus, the same scenario could not be true if a team had performed the project, without experience in SPL. On the other hand, a problem found with this configuration is that the subjects did not present an extensive experience with development of industry SPL projects, and also did not have experience with the addressed domain. Hence, likewise if an experienced team had performed the same project, some risks might have been avoided.

In summary, in order to perform RM in an efficient way, it is necessary commitment by both the risk managers and the development team, since the risks occurrence based on the users actions are the most common during the project development.

\section{Threats to Validity}

Observations: Since only one team member was responsible for the observations, i.e., it is possible that risk manager has not identified some issues occurrence properly.

Subjects Selection: As the selection was based on convenience sampling, we might have not selected the most representative set of subjects, to act as team members. M.Sc. and Ph.D. students, from the same research group of the author, were considered to compose the project team, although it was not stated any expertise requirement before 
the selection. Therefore, not all subjects had previously been involved in industry projects, which could negatively have impacted on the study results.

Project Scenario and Environment: The academic environment was chosen to perform such a project. It indeed hinders the generalization of results, since no industry practice was considered. Software engineering practice strives for data validation through not only toy, but instead real-world projects that offer real data and problems. Thus, it is necessary to apply the RM practices from this academic project into a real project, in order to validate, refine and generalize the results.

\section{Conclusions and Future Work}

Few studies have addressed strategies for avoiding or solving risks in SPL projects if compared to the large amount of research in other SPL issues, or even if compared to $\mathrm{RM}$ in SDD. Thus, in order to reduce the gap on RM in SPL we have been developing empirical studies related to RM in SPL projects, investigating the literature about RM, and performing case studies and survey in order to identify the practices commonly used during risks management in SPL.

There are many benefits for adopting product line engineering as development paradigm, most of them are related to business objectives and organizational issues, since time and costs are decreased, while product quality is increased. However, in order to reach the promised benefits, there are several risks that need to be considered when developing an SPL project, due to its inherent complexity.

The case study performed was designed towards understanding a pool of worth risk management practices to be considered in an SPL project. The case study considered the risks magnitude (status and severity) and descriptions, as well as mitigation and contingency strategies.

Based on the results and on the improvement opportunities identified through this study, it is suggested a future work with a more representative number of participants, in order to refine the proposed RM strategy and to obtain data from a project in a real scenario. Additionally, we intend to combine evidence from different sources of empirical studies (systematic reviews, industrial case studies and expert opinions on RM to SPL) in order to define directions that will serve as base to design new strategies to risk management in SPL projects.

\section{Acknowledgments}

This work was partially supported by the National Institute of Science and Technology for Software Engineering (INES ${ }^{1}$ ), funded by CNPq and FACEPE, grants 573964/2008-4 and APQ-1037-1.03/08 and CNPq grants 305968/2010-6, 559997/2010$8,474766 / 2010-1$.

\section{References}

Birk, A. and Heller, G. (2007). Challenges for Requirements Engineering and Management in Software Product Line Development. Requirements Engineering:

\footnotetext{
${ }^{1}$ INES - http://www.ines.org.br
} 
Foundation for Software Quality, 13th International Working Conference, REFSQ 2007, Trondheim, Norway, June 11-12, 2007, Proceedings. Volume 4542 of Lecture Notes in Computer Science, pages 300-305, Springer, 2007.

Boehm, B. W. (1989). Software risk management. IEEE. Computer Society Press, 1989.

Cavalcanti, Y. C., Machado, I. C., Silveira Neto, P. A. M, Lobato, L. L., E. S. and Meira, S. R. L. (2011). Towards metamodel support for variability and traceability in software product lines, In Proceedings of the Fifth International Workshop on Variability Modelling of Software intensive Systems, Namur, Belgium, 2011.

Clements, P. and Northrop, L. (2001). Software Product Lines: Practices and Patterns. 2001. Boston, MA, USA: Addison-Wesley.

Habli, I. and Kelly, T. (2007). Challenges of Establishing a Software Product Line for an Aerospace Engine Monitoring System. In Proceedings of the 11th International Software Product Line Conference (September 10 - 14, 2007). IEEE Computer Society, Washington, DC, 193-202.

Lobato, L. L. (2012). An approach for Risk Management in Software Product Lines. Ph. D. Thesis. Federal University of Pernambuco, Recife - Brazil, 2012, pp 400p.

Lobato, L. L., O'Leary, P., Almeida , E. S. and Meira, S. R. L. (2010). The Importance of Documentation, Design and Reuse in Risk Management for SPL. In: 28th ACM International Conference on Design of Communication (SIGDOC), 2010.

Lobato, L. L., Machado, I. C., Silveira Neto, P. A. M., Almeida, E. S. and Meira, S. R. L. (2012a). Risk Management in Software Engineering: A Scoping Study. In: 16th International Conference on Evaluation \& Assessment in Software Engineering (EASE), 2012, Ciudad Real, Espanha.

Lobato, L. L., Silveira Neto, P. A. M., Machado, I. C., Almeida, E. S. and Meira, S. R. L. (2012b). Risk Management in Software Product Lines: An Industrial Case Study. In: International Conference on Software and Systems Process (ICSSP), 2012.

Northrop, L. M. (2002). SEI's Software Product Line Tenets. IEEE Softw. 19, 4 (July 2002), 32-40.

Quilty, G., Ó Cinnéide, M. (2011). Experiences with Software Product Line Development in Risk Management. Software Product Line Conference (SPLC).

Runeson, P. and Höst, M. (2009). Guidelines for conducting and reporting case study research in software engineering. Empirical Software Engineering, 14:131-164, April 2009.

Schmid, K. (2002). A comprehensive product line scoping approach and its validation. In Proceedings of the 24th International Conference on Software Engineering, ICSE '02, pages 593-603, New York, NY, USA, 2002. ACM.

Yin, R. K. (2003). Case Study Research: Design and Methods, volume 5. Sage Publications, 2003. 